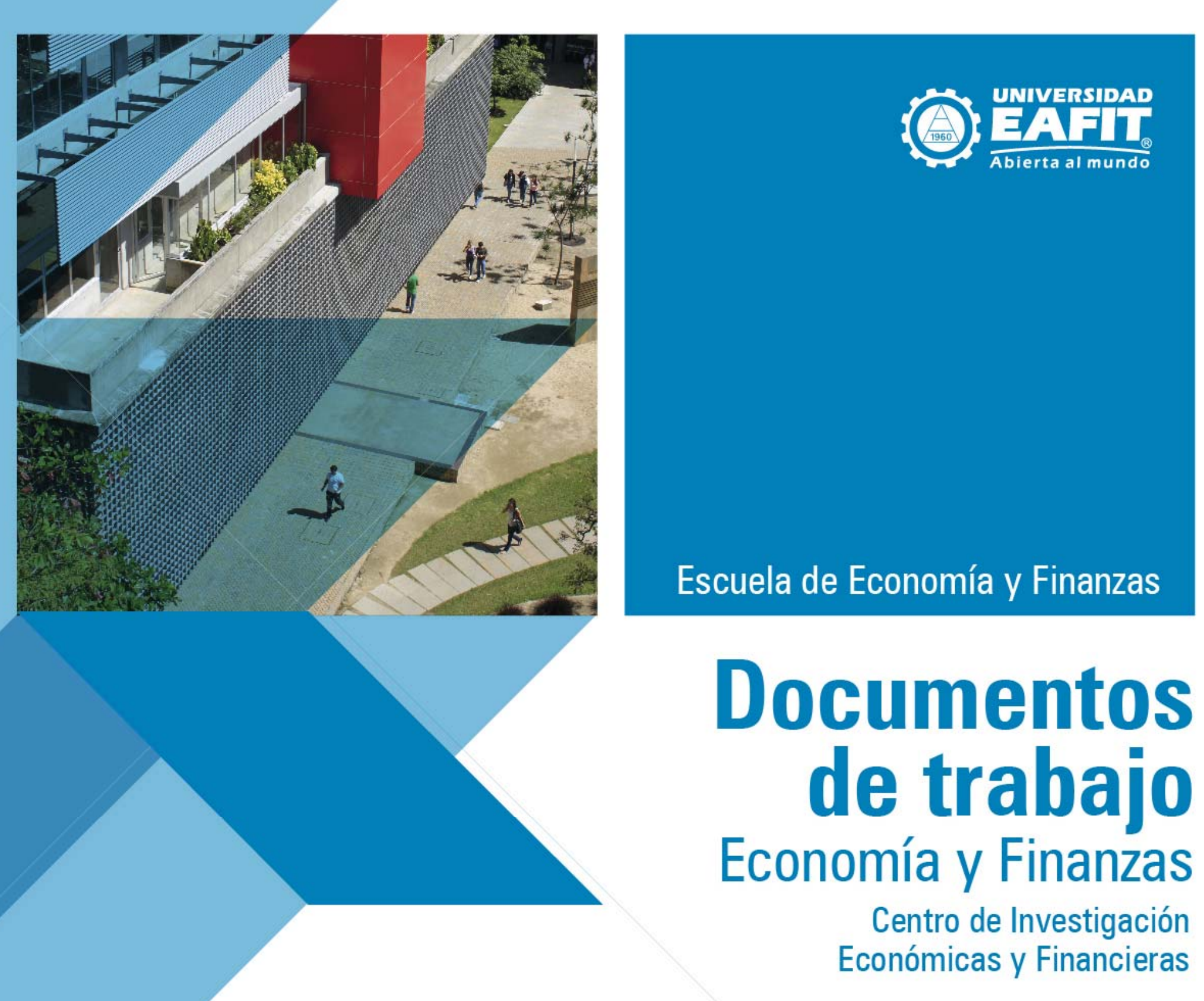

No. 15-16 Evidence that Capital Formation is 2015 Over-Estimated in ICP 2011 Breton, Theodore R. 


\title{
Evidence that Capital Formation is Over-Estimated in ICP 2011
}

\author{
Theodore R. Breton*
}

\author{
Universidad EAFIT
}

July 19, 2015

\begin{abstract}
Using the ICP 2011's cross-country data on input prices and project cost shares, I show that the construction prices in ICP 2011 are substantially underestimated in low and middle income countries. As a consequence, the PPP-adjusted construction in these countries is overestimated on average by about $100 \%$ and gross fixed capital formation as a share of GDP is overestimated by $25-30 \%$. I also examine the ICP 2005 construction prices and show that there are similar problems with the ICP 2005 data.
\end{abstract}

JEL Codes: E30, 047

Key Words: ICP 2011, ICP 2005, construction prices, PPP, construction data, capital data

*Theodore R. Breton, Universidad EAFIT, Carrera 49\#7 Sur-50, Avenida Las Vegas, Medellin, Colombia

ted.breton@gmail.com and tbreton@eafit.edu.co

574-250-5322 (home) 574-261-9334 (office) 574-261-9294 (fax) 


\section{Introduction}

The International Comparison Program (ICP) periodically collects or estimates the prices of goods and services across countries to create estimates of GDP and components of GDP that are adjusted for Purchasing Power Parity (PPP). The prices for the capital formation components of GDP determine the PPP-adjusted share of GDP invested over time. These data are used in cross-country analyses of economic growth.

Capital formation includes two components, machinery/equipment and construction. Estimating national prices for machinery and equipment is relatively straight-forward, since the same, or at least similar, equipment is sold world-wide, but estimating an average construction price is problematic. Construction projects are unique, they vary in composition across countries, and they are rarely sold in arms-length transactions. As a consequence, construction is considered a "comparison-resistant" component of GDP across countries.

The ICP has used several methodologies to estimate construction prices, but it has had a difficult time estimating these prices in low and middle income countries. In ICP 1996 construction prices were not published for these countries because the results were deemed to be unreliable. In ICP 2005 construction prices were to be estimated from input prices and their weights in various construction projects. But since many countries did not provide the required weights, the prices could not be estimated as planned [ICP Global Office, 2011].

In response to the 2005 experience, the ICP decided to use three different methodologies to estimate construction prices for 199 countries in 2011 [World Bank Group, 2015]. The 47 Eurostat-OECD countries regularly estimate construction prices from project cost estimates, and these prices were incorporated directly. The nine CIS countries estimated their construction prices from a model of construction project costs. In the remaining 143 countries, the ICP estimated construction prices from the prices of construction inputs, using a method that linked these input-based estimates to the project-based prices in ten Eurostat-OECD countries. ${ }^{1}$ These ten countries collected prices for the same inputs, but it is not clear how these data were used to link the input-based and project-based estimates.

The ICP has made the construction input prices collected in the 153 countries available to researchers. Given the importance of construction prices for estimating investment rates for use in growth models, I decided to investigate the relationship between the input prices and the ICP 2011's construction prices to see if the approach employed in 2011 provides reasonable results.

\footnotetext{
${ }^{1}$ UK, Finland, Netherlands, U.S., Canada, Denmark, Australia, Portugal, Hungary, and Russia.
} 
In this paper I present the results of my investigation. The results indicate that the ICP 2011 construction prices are substantially underestimated in most of the low and middle income countries. For reasons that I could not determine, on average the construction prices estimated from input prices are only half of what my analysis indicates they should be. As a consequence, in the 143 countries with input-based prices, PPP-adjusted construction is overestimated on average by about $100 \%$ and capital formation as a share of GDP is overestimated by $25-30 \%$.

I revised the input-based construction prices in these countries and then compared the revised set of ICP 2011 prices to the ICP 2005 construction prices. Although economic conditions changed considerably between 2005 and 2011, the price patterns in the two data sets confirm Breton and Garcia's [2015] findings that the ICP 2005 construction prices are too low in the low and middle income countries.

Section II shows the relationship between construction prices and GDP/capita in the ICP 2011 data. Section III presents two methodologies for creating construction prices from input prices, shows the results for 88 countries, and shows that these prices are double the ICP 2011 prices for these countries. Section IV compares the ICP 2005 construction prices to the revised ICP 2011 prices. Section V concludes.

\section{Review of ICP 2011 Construction Prices}

Figure 1 shows the relationship between the ICP 2011 construction prices and GDP/capita for 149 countries that had sufficient data and had a sufficiently large population to provide reliable results. The prices are shown as an index, with the average construction price in the 10 Eurostat-OECD countries as the base. The relationship is shown separately for the construction prices that were created using project-based and input-based methodologies.

The data in the figure show that the construction prices estimated from project estimates are much higher than the construction prices estimated from input prices. The difference is consistently large, regardless of the level of GDP/capita. The trend in the projectbased data indicates that construction prices in low and middle income countries are $60-70 \%$ of the prices in the high-income Eurostat-OECD countries. In contrast, the trend in the inputbased estimates indicate that construction prices in the low and middle income countries are only $30-35 \%$ of prices in these high income countries. This substantial difference suggests that there may have been a problem in the methodology that linked the project-based and inputbased price estimates.

\section{Input-based Price Estimates}


ICP 2011 estimated construction prices for residential, non-residential, and civil engineering types of construction in 143 countries from the prices of construction materials, labor, and equipment [World Bank Group, 2015]. For each type of construction they weighted the average price of inputs in each category by the category's reported share of total project costs to create an average construction price. They then weighted the prices in these three categories by the category's share of total construction to create each country's average construction price.

Figure 1

ICP 2011 Construction Prices vs. GDP/capita

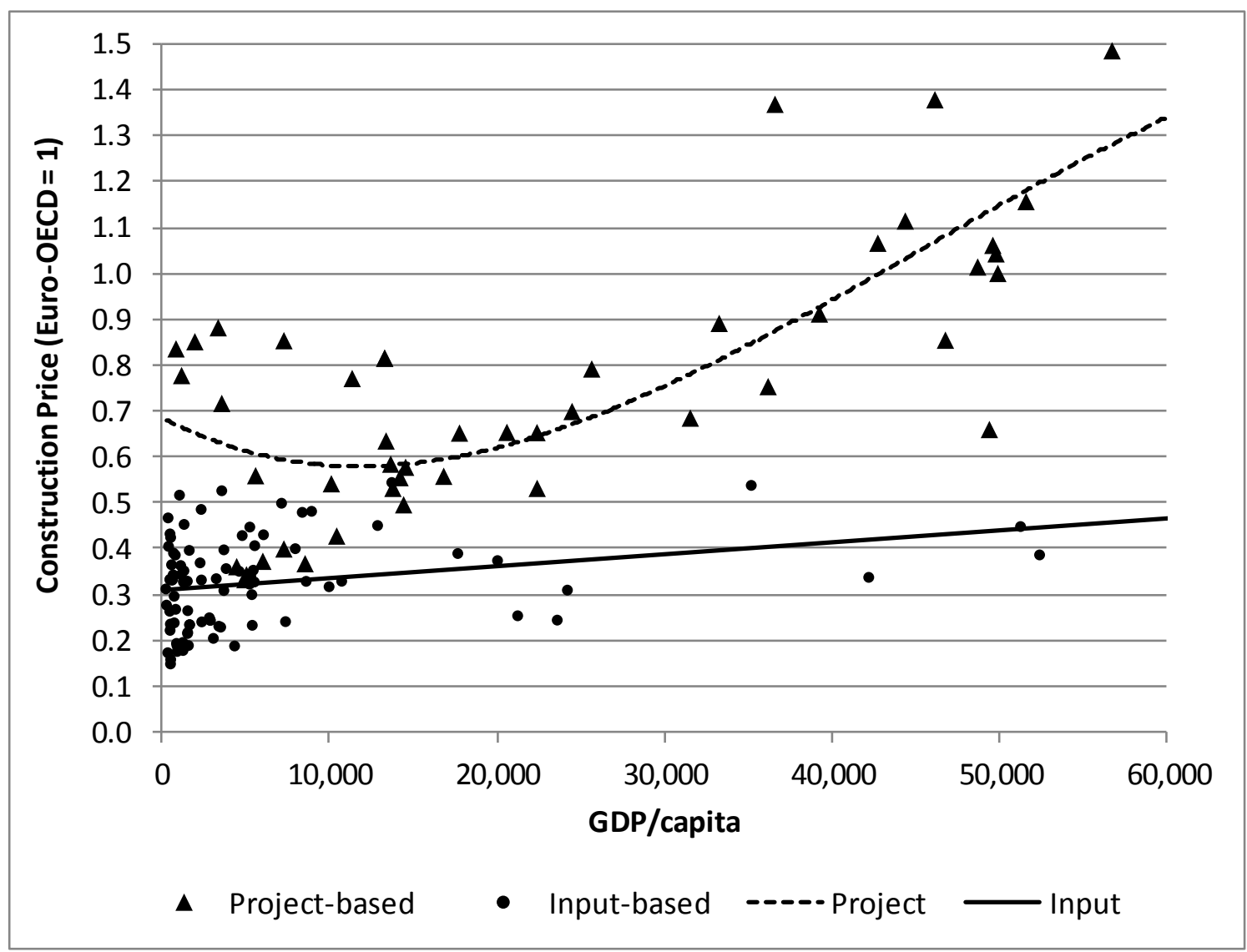

The average prices in the three input categories were estimated from prices for 38 construction materials, seven labor categories, and numerous types of equipment. The prices of missing items were estimated prior to the estimation of the average price. Input prices were 
not weighted to create the average price in each category, but only inputs deemed relevant for a particular kind of construction were included in the calculation of its average price.

The ICP has not provided all of the data and the details of the methodology that would be required to replicate their input-based prices, and I have not attempted to replicate the sophisticated techniques used to create these prices. Instead I have used arithmetic averages of indexed prices and trends in these indexed prices to estimate the relative average price of non-residential construction as a function of GDP/capita for 88 countries. These calculations are not precise, but they are sufficiently accurate to show that the ICP's sophisticated techniques somehow created input-based construction prices that are far too low.

Figure 2 shows the trends in the average indexed price of materials, labor, and equipment in the 88 countries as a function of GDP/capita. The prices are expressed as an index based on the average price of inputs in these categories in the ten Eurostat-OECD countries where the ICP collected input prices. The labor price is the average hourly price of labor. The equipment price is the ICP's estimate of national equipment prices for all types of equipment, not just for construction-related equipment.

Figure 2

ICP 2011 Average Prices of Construction Inputs vs. GDP/capita

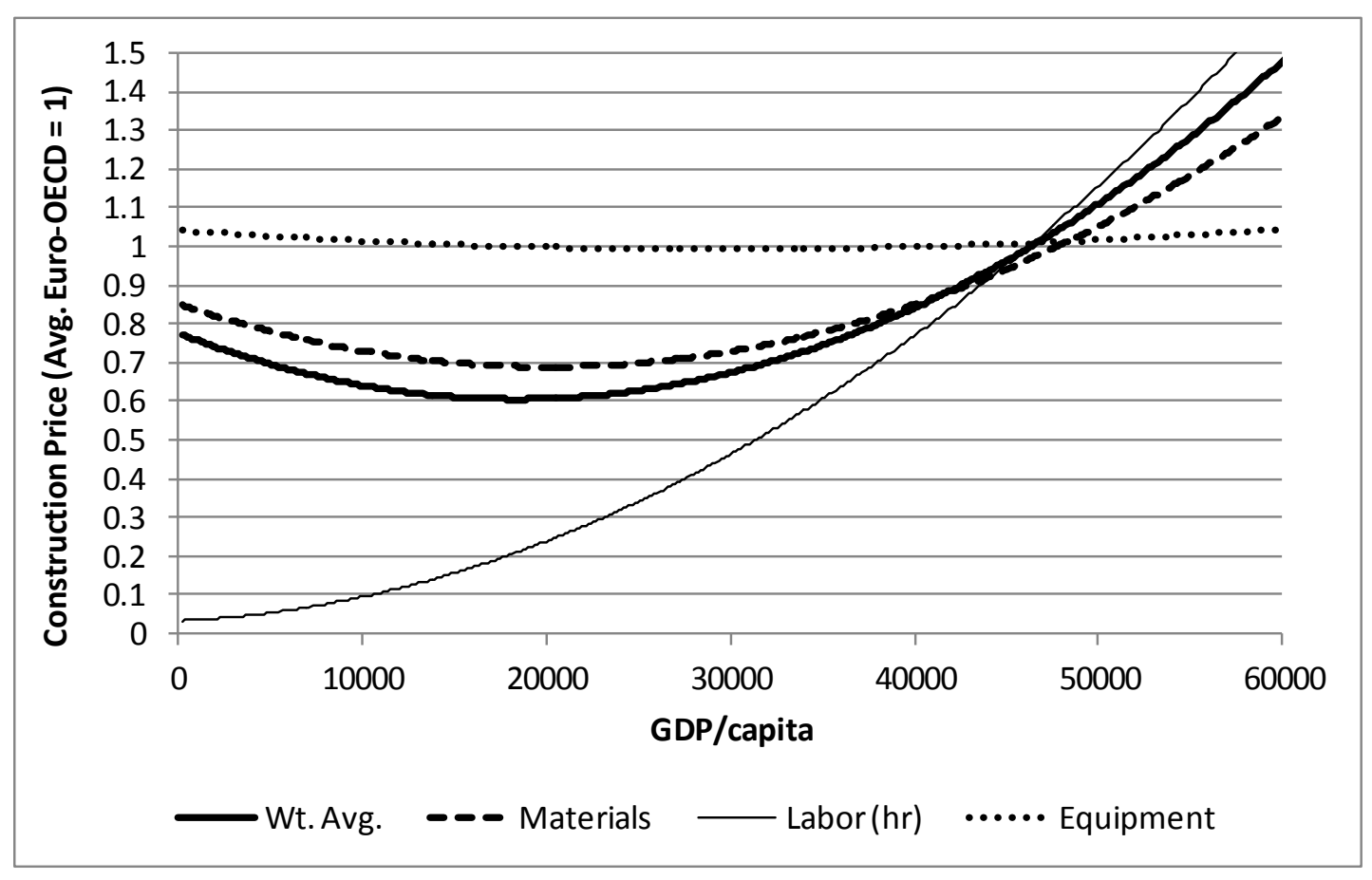


The 88 countries used in the comparison are those that had a population of at least 1 million and prices for enough materials and types of labor to estimate a reliable average price. I excluded Singapore and four Middle Eastern countries with high GDP/capita from the comparison to ensure that the prices at high levels of GDP/capita are representative of the Eurostat-OECD countries.

The three categories of components have very different price patterns. Equipment prices are similar across countries. Labor prices (per hour) are extremely low in the low income countries and rise substantially with increases in GDP/capita. Materials prices are lowest in countries with a GDP/capita of about $\$ 18,000$. These countries produce construction materials at reasonable scale with relatively low labor costs, so they can supply materials at lower cost than either the lower or higher-income countries. Overall, however, materials prices are not that low in low and middle income countries relative to high-income countries.

The World Bank Group [2015] states that input-based construction prices were estimated in each country by weighting the average materials' prices and the unit labor and equipment prices (i.e., cost/hour) using the reported share of each input category in total project costs. Figure 2 shows my estimates of the weighted average price of the three types of inputs, using the reported or estimated share of each type of input in total project costs in each country.

The weighted average input price in each country is similar to the average materials price because materials compose the largest share of total project costs. The weighted input prices in the low and middle income countries (I,e., GDP/capita < 12,000 USD) are $60-75 \%$ of the weighted input price in the 10 Eurostat-OECD countries. This relationship is very similar to the relationship in the project-based price estimates in Figure 1, but surprisingly, it is not at all like the ICP's estimates of input-based prices.

Table 1 shows the ICP 2011's initial estimates of the materials, equipment, and labor shares of total project costs [ICP Global Office, 2011] and the average reported shares for nonresidential construction for low, middle, and high income countries in the input data [ICP 2011, 2015]. Material costs depend on the mix of materials and prices used in each country. The labor and equipment cost shares are determined by the unit prices (i.e., cost/hour) and the total hours for these types of components. Total hours for labor and equipment vary across countries, depending on labor and equipment productivity.

Despite the considerably lower unit labor prices in the low and middle income countries, their reported average labor share of total project costs is not that much lower than the share in the high-income countries (21-24\% vs. $32 \%$ ). The very low unit labor prices in the low and middle income countries implicitly are offset by their low labor productivity. This is consistent 
with Breton and Garcia's [2015] estimate that Colombian labor productivity in multi-story building construction is $25-30 \%$ of U.S. productivity.

\begin{tabular}{|l|c|c|c|c|c|c|}
\hline \multicolumn{7}{|c|}{ Table 1 } \\
\hline \multirow{2}{*}{$\begin{array}{l}\text { Income } \\
\text { Group }\end{array}$} & \multicolumn{3}{|c|}{ ICP 2011 Estimates } & \multicolumn{3}{c|}{ Average Reported Shares } \\
\cline { 2 - 7 } & Materials & Equipment & Labor & Materials & Equipment & Labor \\
\hline High & 60 & 10 & 30 & 55 & 13 & 32 \\
\hline Middle & 65 & 10 & 25 & 62 & 14 & 24 \\
\hline Low & 65 & 15 & 20 & 63 & 16 & 21 \\
\hline
\end{tabular}

Since labor productivity is much lower in low and middle income countries, the ICP's methodology of weighting unit labor prices, rather than productivity-adjusted labor costs, underestimates labor costs in the low and middle income countries relative to the ten EurostatOECD countries. The ICP'S assumption that total factor productivity (TFP) in construction is the same across countries [World Bank Group, 2015] almost certainly underestimates the actual construction price in the low and middle income countries.

I develop an alternative estimate of construction prices using the same input prices and project cost shares in a different methodology. I estimate a country's total project cost by increasing the average materials' price by the reported non-materials' share of total project costs:

\section{1) $\quad$ Project cost $=$ Avg Materials Price/Materials Share of Project Costs}

This methodology implicitly assumes that all countries use the same mix of materials to create a non-residential structure. The data on reported cost shares in Table 1 shows that the average project cost in the high-income countries is $1 / 0.55=1.82$ times the materials' cost. In the low and middle income countries, the average project cost is $1 / 0.63=1.59$ times and $1.0 / 0.62=$ 1.61 times the materials' cost.

I then create an index of each country's total project cost relative to the average project cost in the ten Eurostat-OECD countries. This approach accounts for labor and equipment productivity differences across countries, but it assumes there is no substitution of lower cost labor for materials in the low and middle income countries. Since some substitution of labor for materials is likely in these countries, this methodology likely overestimates the relative cost of materials (and simultaneously, the cost of labor and equipment) in these countries. As a consequence, the ICP's weighted input methodology and this materials-based methodology likely bracket the actual construction price in low and middle income countries relative to the high-income countries. 
Figure 3 shows the published ICP 2011 prices, the weighted input prices, and the materials-based input prices, as a function of GDP/capita. In the middle income countries (i.e., GDP/capita between 1,000 and 12,000 USD), the materials-based input prices exceed the weighted input prices by $2-10 \%$ of the Eurostat-OECD price. In the low income countries, the two methods produce virtually identical prices. More importantly, the average of these two input-based estimates is about double the published ICP 2011 prices for these countries and almost identical to the to the project-based construction prices in Figure 1.

Figure 3 also shows the project-based prices for eight of the ten Eurostat-OECD countries in which input prices were collected. ${ }^{2}$ Since these countries have much higher GDP/capita than the low and middle income countries, it is not evident how these projectbased prices were linked to the input-based prices in the low and middle income countries. It appears that the linking method did not extrapolate the Eurostat-OECD prices to countries with a lower GDP/capita in a valid manner.

Figure 3

ICP 2011 Construction Prices vs. Input-Based Estimates

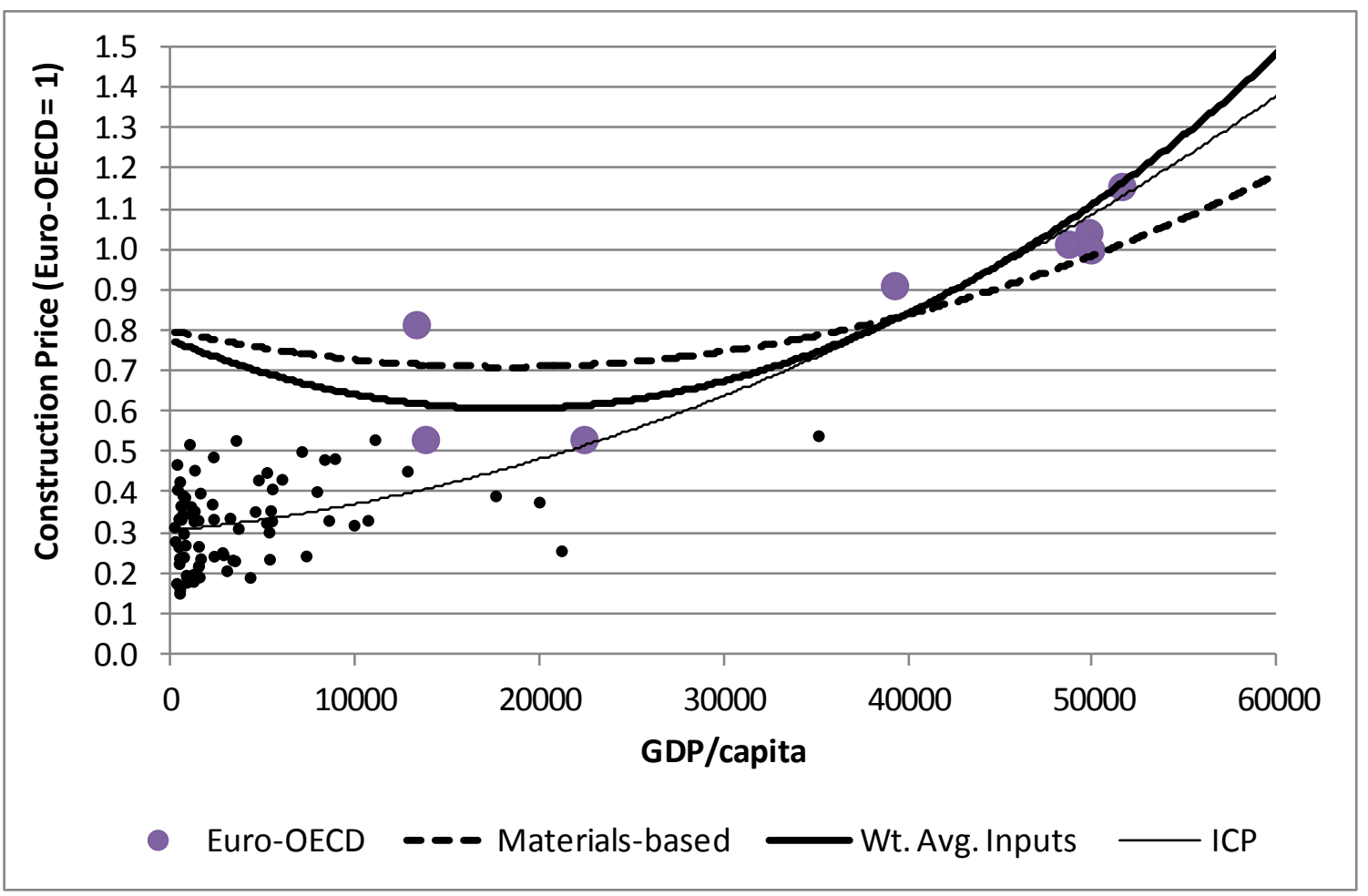

\footnotetext{
${ }^{2}$ Denmark and Australia have GDP/capita above $\$ 60,000$.
} 
The ICP's underestimate of construction prices in the low and middle income countries leads to an overestimate of PPP-adjusted construction, which causes an overestimate of capital formation. Figure 4 shows the ICP's estimates of gross fixed capital formation real expenditures as a share of total real expenditures for these countries [World Bank Group, 2015] and revised estimates based on the average of the two input-based construction prices shown in Figure 3.

The revisions reduce average gross fixed capital formation from $23 \%$ of GDP to $17.5 \%$ in the low income countries and from $22.5 \%$ to $18 \%$ in the middle income countries. These estimates are only approximate because the ICP's GEKS-based real expenditures are not additive within countries, but they indicate that gross fixed capital formation in these countries is overestimated by $25-30 \%$. This overestimate is large enough to have serious implications for economic analyses that involve low and middle income countries.

Figure 4

ICP 2011 Published and Revised Capital Formation as a Share of GDP

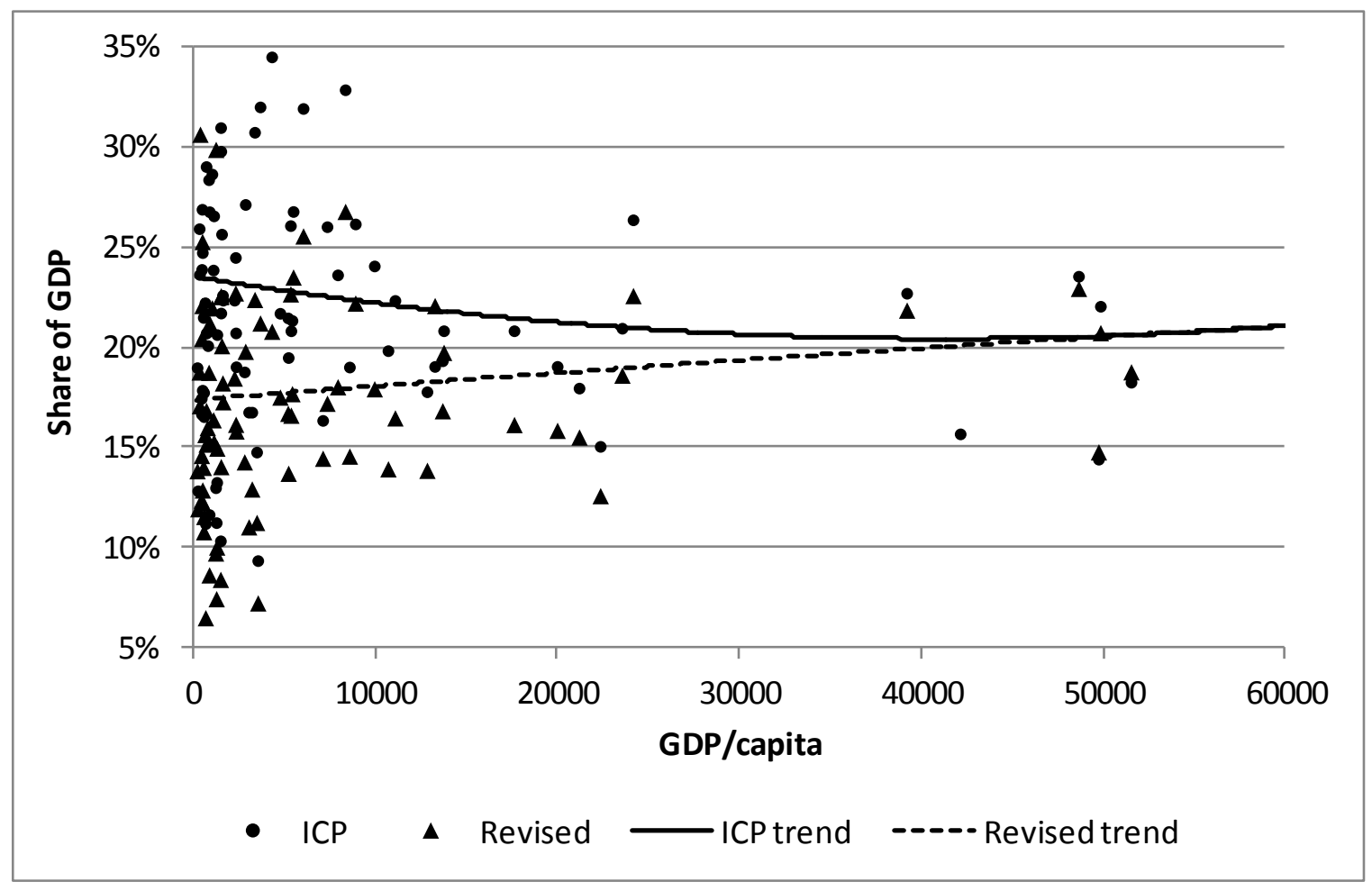

\section{Comparison with ICP 2005 Construction Prices}


Breton and Garcia [2015] present evidence that construction prices in ICP 2005 were underestimated in low and middle income countries, but they did not have access to the input prices the ICP used to estimate construction prices in 2005. Economic conditions changed considerably between 2005 and 2011, but arguably the relationship between construction prices in low and high income countries in 2005 was similar to this relationship in 2011.

Figure 4 shows how the ICP 2005 prices (indexed to the average prices in the EurostatOECD countries) compare to the revised ICP 2011 prices, using the 2011 GDP/capita for each country in both years. The revised ICP 2011 prices are the project-based prices and the average of the two input-based estimates for the countries with input-based prices.

\section{Figure 4}

Revised ICP 2011 vs. ICP 2005 Construction Prices

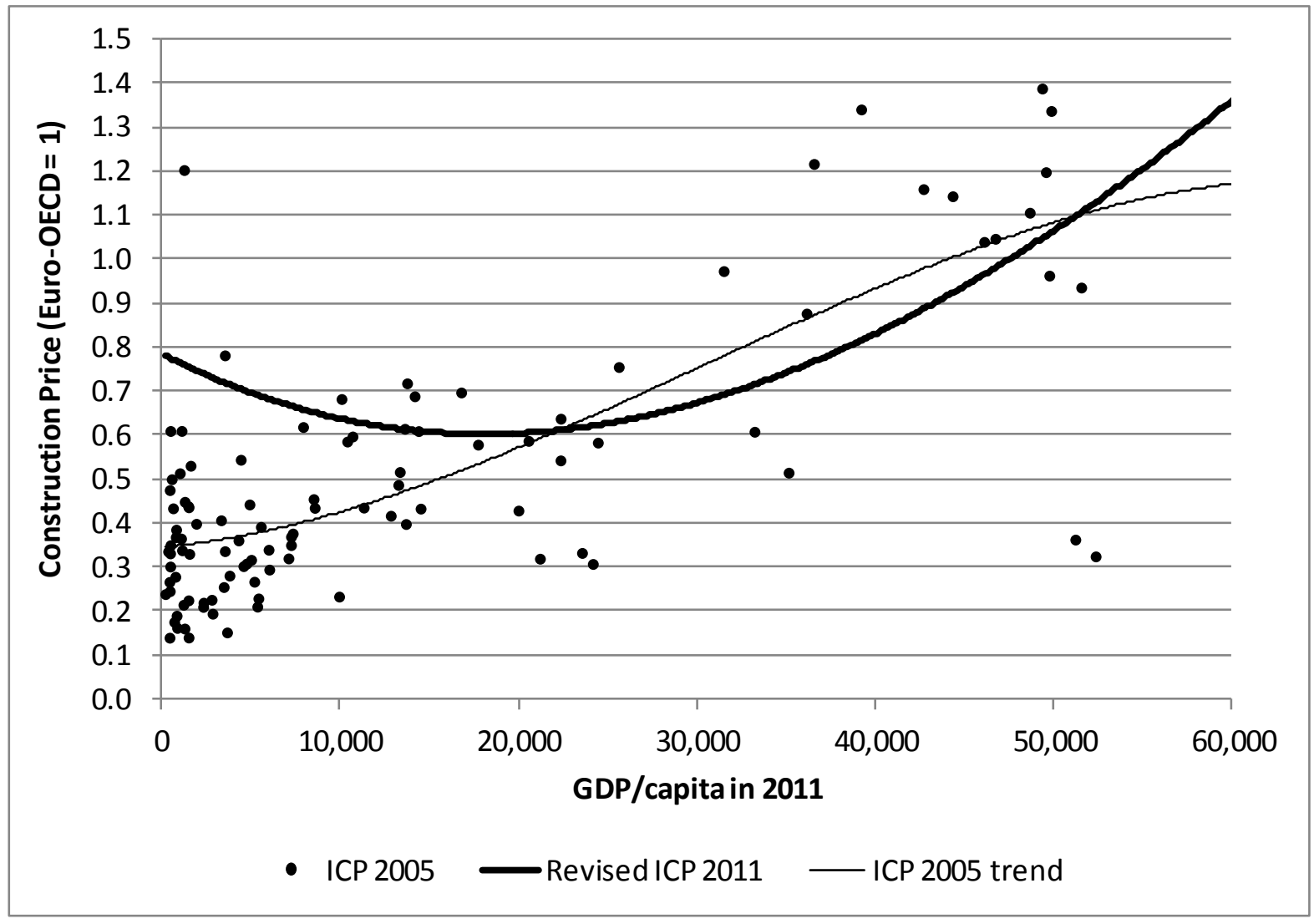

The patterns in Figure 4 are consistent with Breton and Garcia's [2015] conclusions that ICP 2005 construction prices are underestimated in low and middle income countries. The ICP 
2005 prices are only half of the revised ICP 2011 prices in the low income countries. The ICP 2005 prices are also lower than the revised ICP 2011 prices in the middle income countries, but the underestimate is smaller than in the low income countries.

\section{Conclusions}

ICP 2011 estimated construction prices using several methodologies. An analysis of these prices shows that in countries with the same levels of GDP/capita, the ICP prices created from input prices are much lower than the ICP prices created from project prices.

Using the ICP 2011 cross-country data on input prices and project cost shares, I show that the ICP 2011 input-based construction prices are only half what they should be. As a result, ICP 2011 overestimates PPP-adjusted construction by over 100\% in the countries where construction prices were estimated from input prices. This overestimate leads to a $25-30 \%$ overestimate of gross fixed capital formation as a share of GDP in these countries.

A review of the ICP 2005 construction prices reveals that the data patterns are similar to the ICP 2011 data. Although economic conditions were different in 2005 than in 2011, the ICP 2005 construction prices also appear to be underestimated in low and middle income countries relative to the Eurostat-OECD countries.

A 50\% reduction in the ICP 2011's estimate of construction investment in low and middle income countries would reduce estimates of aggregate capital stocks and capital/output ratios estimated using the ICP data. The lower share of construction in gross fixed capital formation would raise the average capital depreciation rate. The reduced size of the capital stock would raise the estimated TFP in the low and middle income countries. As a consequence, economic growth analyses involving low and middle income countries that use the ICP 2005 and ICP 2011 capital formation data are likely to have biased results. 


\section{References}

Breton, Theodore R., and Garcia, John J., 2015, "ICP 2005 Construction Prices: Are They Underestimated in Developing Countries?" Review of Income and Wealth, forthcoming, published online in January 2015

ICP 2011, 2015,"2015-03-10_ICP 2011 data revised 5-18-2015," provided by Marko Olavi Rissanen by email

ICP Global Office, 2011, "A New Approach to International Construction Price Comparison," Operational Material, http://siteresources.worldbank.org/

World Bank Group, 2015, Purchasing Power Parities and the Real Size of World Economies, Washington, D.C. 